\title{
Virtual reality therapy for rehabilitation of balance in the elderly: a systematic review and META-analysis
}

\author{
Juleimar Soares Coelho de Amorim ${ }^{1,4^{*}}$, Renata Cristine Leite ${ }^{2}$, Renata Brizola ${ }^{2}$ and Cristhiane Yumi Yonamine ${ }^{3}$
}

\begin{abstract}
Virtual reality therapy (VRT) has clinical indications in rehabilitation programs for the elderly; however, there is still no consensus on the recovery of body balance. The objective of this review was to summarize the effects of physical therapy interventions with VRT in the rehabilitation of balance in the elderly. The studies were identified via a systematic search in the databases PubMed, SciELO, LILACS and PEDro from 2010 onward. Clinical trials with interventions that involved VRT in the elderly were included in the study and were subjected to methodological quality analysis using the PEDro scale. A random effects meta-analysis of the studies that analyzed balance using the Berg Balance Scale and the Timed Up and Go (TUG) test was performed. Ten articles met the inclusion criteria, which presented variability in relation to the types of interventions used (70\%) and the outcomes analyzed (60\%). The mean duration of the interventions was 13.90 ( \pm 5.08) weeks, with at least two weekly sessions $( \pm 0.73)$. There were positive results in relation to improvements in both dynamic and static balance (70\% of the studies), mobility (80\%), flexibility (30\%), gait (20\%) and fall prevention (20\%). A summary of the meta-analysis showed mean effects on the Berg scale (standardized mean difference [SMD]: $-0.848 ; 95 \% \mathrm{Cl}:-1.161 ;-0.535)$ and the TUG test (SMD: 0. 894; $95 \%$ Cl: $0.341 ; 1.447)$. Individually, virtual reality is promising in rehabilitation programs for the elderly. The overall measures were sufficient to show beneficial effects of the therapy on balance in the elderly.
\end{abstract}

Keywords: Virtual reality exposure therapy, Postural balance, Rehabilitation, Physiotherapy modalities, Elderly

\section{Background}

The speed of population aging has led to challenges for the health system, especially with regard to interventions to maintain functional capacity and independence and to broaden the framework of rehabilitation professionals. Mobility, body balance (static and dynamic), gait, joint and lower limb muscle flexibility are indicated as musculoskeletal attributes that support functional capacity in the elderly [1]. The loss or decline of balance results in a major public health problem: falls. The imbalance results from interactions of the musculoskeletal, visual, and sensorimotor systems and related functional tasks that undergo changes with senescence, such as sarcopenia, proprioceptive alterations, joint stiffness, postural

\footnotetext{
* Correspondence: juleimar@yahoo.com.br

${ }^{1}$ Ciências da Reabilitação, Instituto Federal de Educação, Ciência e Tecnologia do Rio de Janeiro - IFRJ, Rio de Janeiro, RJ, Brasil

${ }^{4}$ Colina, Manhuaçu, Brazil

Full list of author information is available at the end of the article
}

alignment, latency and temporal incoordination of muscle activation [1-4].

Orthopedic, rheumatologic and neurological diseases are responsible for compromising postural control and mobility, implying greater body oscillation. Similarly, healthy individuals may also suffer from balance disorders due to their own senescence, such as reduced neuromuscular response speed, motor planning, joint degeneration, bone density and sarcopenia. However, these changes should not result in bone fractures, soft tissue injuries or traumatic brain injury due to the occurrence of falls. Therefore, preventive and rehabilitative measures are necessary for the maintenance of the joint and musculoskeletal system [2-4].

Scientific evidence from the scope of physiotherapeutic rehabilitation points to kinesiotherapy for motor coordination, balance training, stretching, muscle strengthening and functional training as approaches capable of preventing functional capacity declines in the

(c) The Author(s). 2018 Open Access This article is distributed under the terms of the Creative Commons Attribution 4.0 International License (http://creativecommons.org/licenses/by/4.0/), which permits unrestricted use, distribution, and 
elderly [5]. However, technological advances, including Virtual Reality Therapy (VRT), which employs games as a resource to help individuals with balance deficits through the use of electronic devices experienced by the "human-machine interface", have modernized the clinical practices of rehabilitation professionals [6-8].

VRT rehabilitation has received increasing attention from researchers and clinicians who recognize its benefits because of its therapeutic potential regarding falls prevention and balance rehabilitation $[8,9]$. The easy applicability, the stimuli to the sensory and motor systems and the playful character of the therapy offer a high degree of motivation, pleasure and instantaneous feedback on the execution of the tasks. Thus, VRT stimulates functional activities, promotes social interaction when administered collectively and may encourage the adherence of the elderly to rehabilitation programs [8-10].

The patient's movements are captured by a sensor bar or camera and are similar to those performed in daily life activities, facilitating motor recovery. These movements generally simulate sports practices, and to effectively perform the game, the patient is challenged to perform movements that strengthen the muscles, stimulate brain activity, improve sensory response and increase concentration, balance, motor coordination, motor control and gait efficiency [10].

Contradictory results have been reported in the literature, and VRT dissemination is still incipient $[6,7]$. Evidence of the positive and negative effects of virtual reality can prod physiotherapists to broaden their scope of action in the provision of care during rehabilitation of the elderly. Therefore, a literature review can provide information on which domains of functional rehabilitation have demonstrated effective interventions using VRT. This therapy has not yet received a structured critique for improving body balance. Therefore, the objective of this review was to evaluate and synthesize the effects of physiotherapeutic interventions with VRT in balance rehabilitation of the elderly.

\section{Materials and methods}

The systematic review identified and selected studies published in Portuguese, English and/or Spanish. Four search themes were combined using the Boolean operators "AND" and "OR". The first search was on virtual reality therapy, combined in the title/abstract from the key words "Virtual Reality Exposure Therapy" or "Video Game" and "Rehabilitation" or "Physical Therapy" or "Physiotherapy Modalities". Next, we identified the studies with samples of elderly individuals using the term "Elderly". The third search included the outcomes "Postural Balance" and/or "Proprioception". Finally, "Clinical Trial" studies were selected as the type of publication. All the keywords were extracted from the Health
Descriptors (Descritores em Saúde - DeCS), and the search adopted its equivalents in English and Spanish. The search was performed in the electronic databases MEDLINE via PubMed, EMBASE, SciELO, LILACS and PEDro. The search ended in August 2016.

Clinical trial and controlled or randomized clinical trial articles published from 2010 onward with sample compositions that contained elderly subjects and that used VRT as a method of balance rehabilitation were included. Studies with interventions that were not specific to physical therapy or that presented preliminary data, pilot studies, interventions for vestibular rehabilitation (dizziness, labyrinthitis, vertigo), review articles, case studies, theses and dissertations were excluded.

The materials were selected by two independent reviewers who analyzed the title, the abstract and then the text in full, in this sequence; in cases of disagreement, a third reviewer was asked for consensus. To analyze the methodological quality of the studies, the PEDro scale was used. This scale is a checklist widely used in the area of rehabilitation, elaborated by the database Physiotherapy Evidence Database Research, which is specific for studies that investigate the effectiveness of interventions in physical therapy [11]. The scale has a total score of 10 points, with scores $\geq 5$ considered to be of high quality.

The following data were extracted from the studies from a form that was specifically developed to analyze the data, adjusted by authors' interest as recommended by the Cochrane Library [12]: information about the author, year of publication, research objective, sample composition (size, diagnoses and age group), evaluation instruments, intervention measures (combined VRT or VRT alone), comparison, randomization process, intention-to-treat analysis, loss control and sample calculation, blinding process, number of sessions, weekly frequency, mean duration of therapy and the main results found. The final evaluation of the quality of the evidence was verified by the GRADE (Grading of Recommendations Assessment, Development and Evaluation) System, which establishes a consensus about the quantification of the quality of the evidence and of the recommendation strength in high, moderate, low or very low levels [13].

Articles that presented complete data regarding the evaluation and results (means and standard deviations) of the body balance construct and that presented homogeneity in the outcome measure were combined to perform the random effects meta-analysis using Stata13.1 software (StataCop 2013. College Station, TX: StatCopLP). The standardized mean difference (SMD), its 95\% confidence intervals and the effect size (Overall Z) were used to estimate the effectiveness of the VRT intervention, with a value of $p<0.05$ being considered statistically significant. The heterogeneity of the studies was 
evaluated by the value of the $I^{2}$ statistics, the $p$-value obtained by the Cochran $\mathrm{Q}$ test, the tau-square estimate and the difference between means, and those with $p$ values $>0.05$ were considered homogeneous.

\section{Results}

The search resulted in 486 articles in the MEDLINE, EMBASE, SciELO, LILACS and PEDro databases, of which only 24 met the inclusion and exclusion criteria for reading in full. The final sample of studies consists of 10 articles, as summarized in Fig. 1.

The characteristics of the selected articles regarding the intervention and the outcomes and results are presented in Table 1 . There was variability in relation to the type of intervention used and the outcomes analyzed, in which seven different types of interventions were verified (proprioceptive training, aerobic training, static and dynamic balance, muscle flexibility, yoga and strengthening). The mean sample size was $31.40( \pm 13.75)$ participants, with a minimum age of $62.22( \pm 4.41)$ years old and a maximum of 87.40 ( \pm 6.02 ) years old; eight $(80 \%)$ studies performed interventions with the elderly without reporting specific diseases (healthy), one study (10\%) was on Parkinson's disease, and one study $(10 \%)$ was on diabetes mellitus. The mean duration of the sessions was $13.90( \pm 5.08)$ weeks, with a mean weekly frequency of
$2.10( \pm 0.73)$ times and an average duration of $37( \pm$ $10.85)$ minutes.

Two studies (20\%) analyzed the results by intention to treat, and $30 \%$ of the articles had post-intervention follow-up for a mean time of 4.66 weeks $( \pm 1.15)$. In all studies, there was randomization with a control group; $20 \%(N=2)$ had a blinded evaluator, $30 \%(N=3)$ used combination therapy, $80 \%$ referred to sample calculation $(N=8)$, and the mean score in the PEDro scale equal was to $6.80( \pm 1.135)$ points. The main instruments for measuring the outcomes were the Berg balance scale $(60 \%, N=6)$, Timed $U p$ and Go (TUG) $(60 \%, N=6)$, unipedal support $(40 \%, N=4)$ and functional range $(30 \%, N=3)$ (Table 2).

The effectiveness of the intervention was present in $70 \%$ of the individuals who performed VRT, the main effects being improvements in balance (dynamic and static) $(80 \%, N=8)$, mobility and flexibility $(30 \%, N=3)$ and gait $(20 \%, N=2)$ and a reduction in falls $(20 \%, \mathrm{~N}=$ 2 ). Table 2 shows the variation in the choice of instruments for measuring these outcomes. To systematize the results in relation to the main domains of balance and based on the proportion of studies that adopted specific instruments to assess the efficacy of the therapy, the balance and mobility outcomes were measured, respectively, using the Berg Balance Scale and the TUG

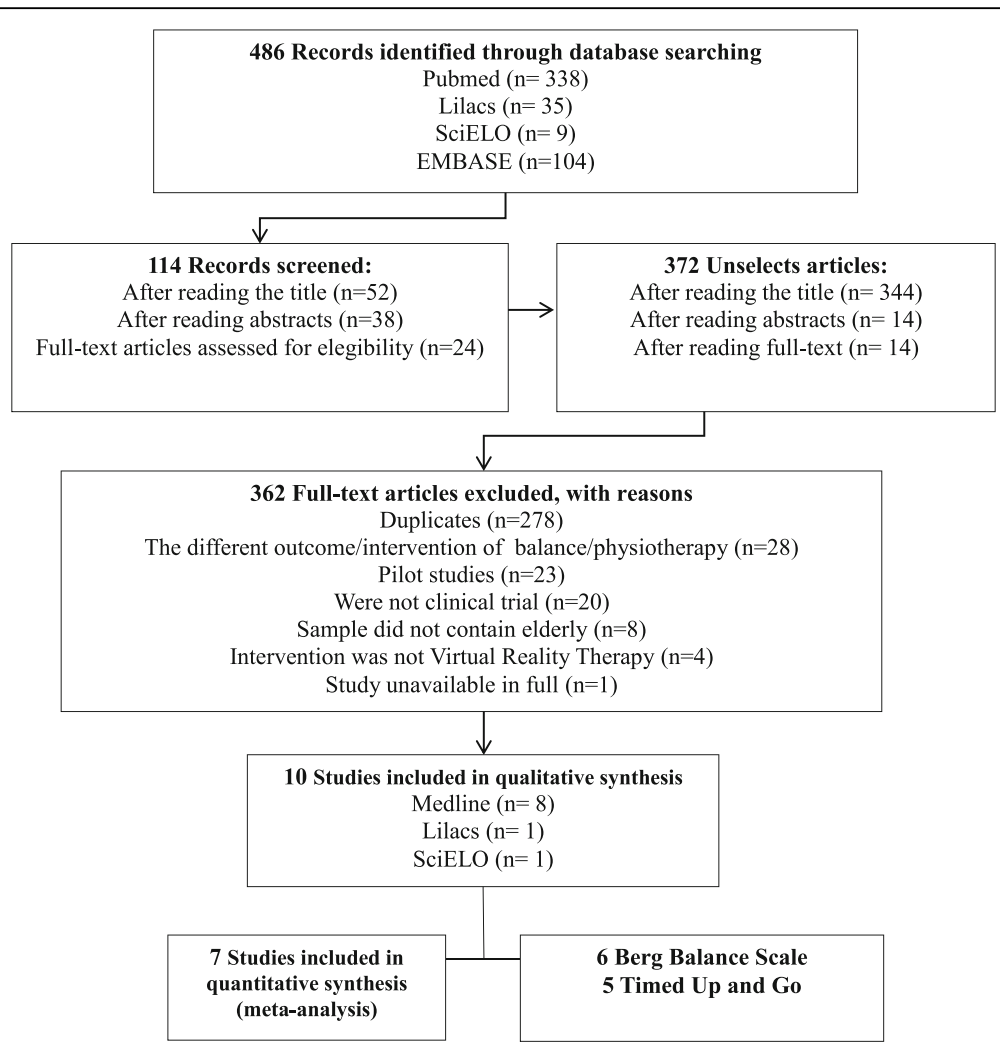

Fig. 1 Preferred Reporting Items for Systematic Reviews flow diagram of the studies included in our overview 


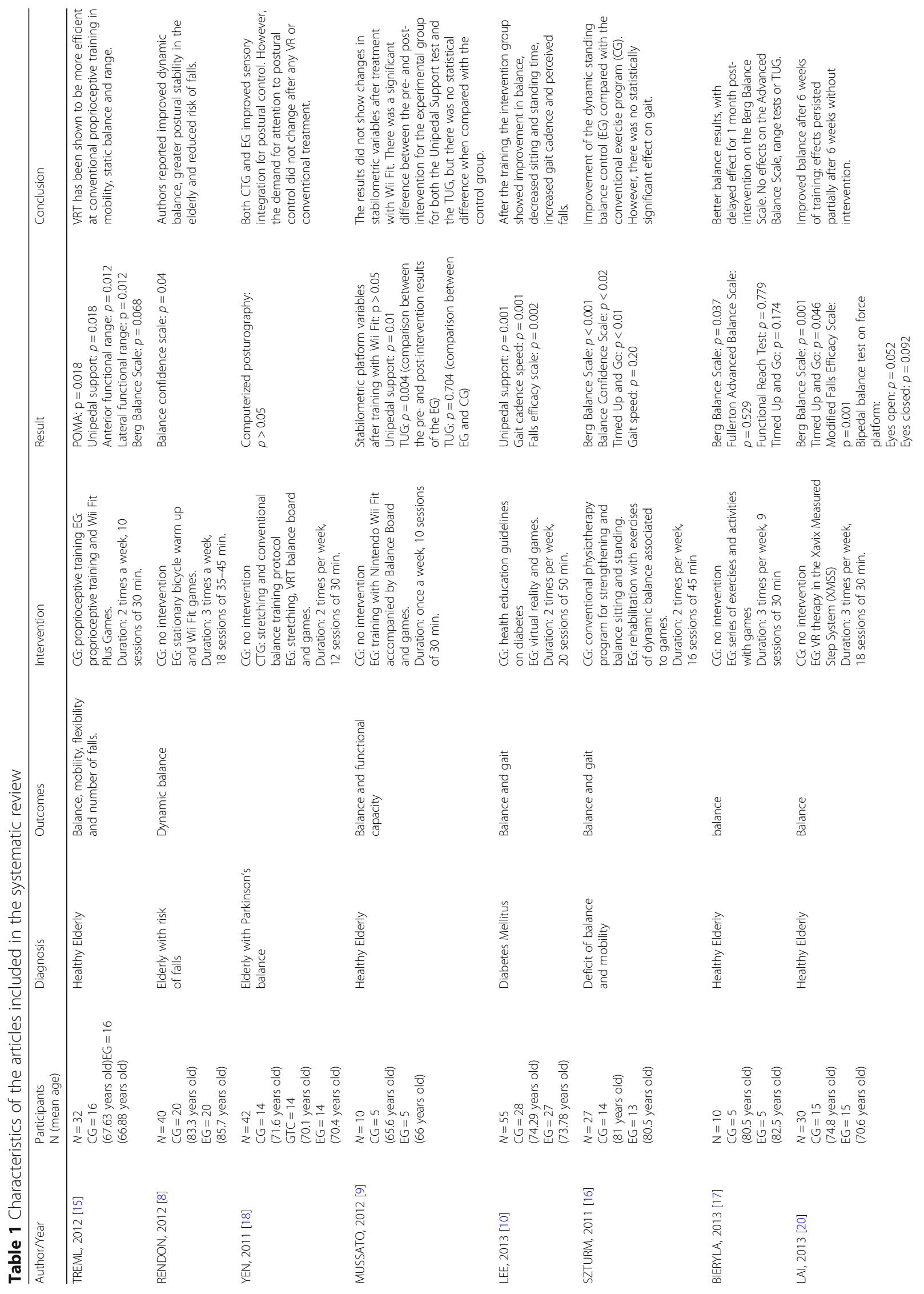




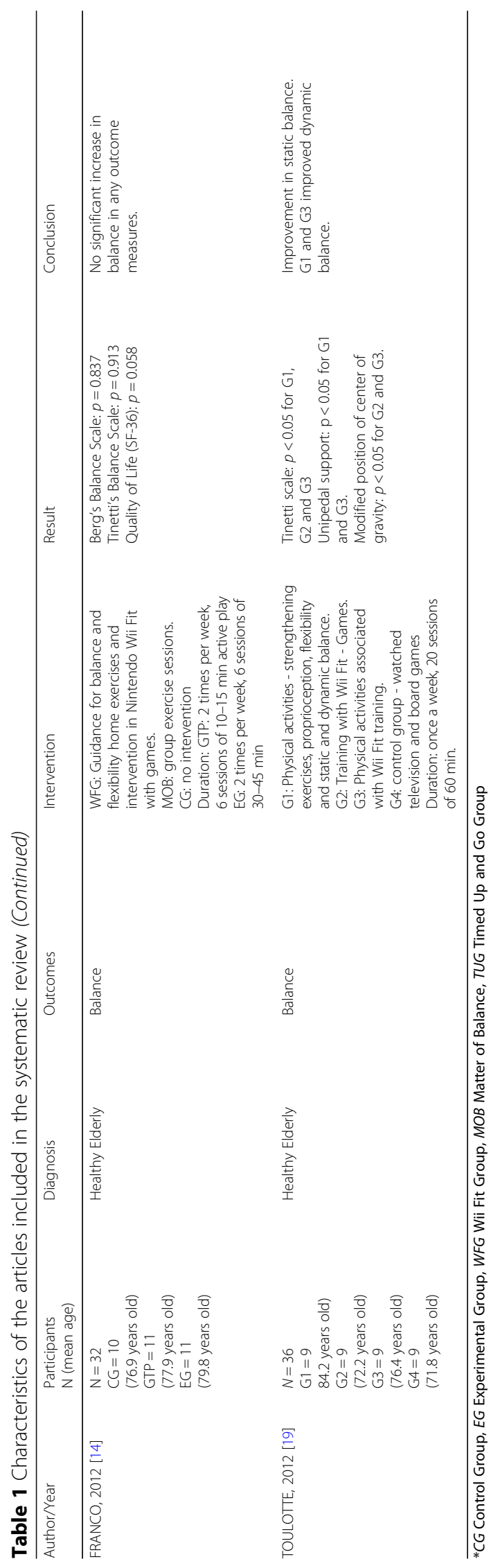


Table 2 Studies included in the systematic review: analysis of the methodological quality, instruments and equipment to perform the therapy

\begin{tabular}{|c|c|c|c|}
\hline Author/Year & PS & Outcome evaluation tools & Virtual Reality Therapy \\
\hline TREML, 2012 [15] & 7 & $\begin{array}{l}\text { Berg Balance Scale; Functional Range; } \\
\text { Performance Oriented Gait and Balance } \\
\text { Assessment; Unipedal Support }\end{array}$ & $\begin{array}{l}\text { Nintendo Wii console associated with Balance } \\
\text { Board and Wii Fit games }\end{array}$ \\
\hline RENDON, 2012 [8] & 6 & $\begin{array}{l}\text { TUG; Balance of Confidence Scale; } \\
\text { Geriatric Depression Scale }\end{array}$ & $\begin{array}{l}\text { Nintendo Wii console associated with Balance } \\
\text { Board and Wii Fit games }\end{array}$ \\
\hline YEN, 2011 [18] & 7 & $\begin{array}{l}\text { Dynamic computerized posturography: } \\
\text { Standing sensory organization test, } \\
\text { sitting cognitive test and sensory } \\
\text { organization test and standing } \\
\text { cognitive test }\end{array}$ & $\begin{array}{l}\text { Balance board, LCD monitor and a personal } \\
\text { computer }\end{array}$ \\
\hline MUSSATO, 2012 [9] & 7 & $\begin{array}{l}\text { Stabilometric Platform (Baropodometry), } \\
\text { Unipedal Support and TUG. }\end{array}$ & $\begin{array}{l}\text { Nintendo Wii console associated with Balance } \\
\text { Board and Wii Fit games }\end{array}$ \\
\hline LEE, 2013 [10] & 7 & $\begin{array}{l}\text { Unipedal Support, Berg Balance Scale, } \\
\text { Functional Range, TUG, Sitting and } \\
\text { standing up, Gait Rite System, Falls } \\
\text { Efficacy Scale }\end{array}$ & $\begin{array}{l}\text { PlayStation } 2 \text { with the EyeToy accessory: } \\
\text { Play 1.2, 3" (Sony Computer Entertainment) }\end{array}$ \\
\hline SZTURM, 2011 [16] & 8 & $\begin{array}{l}\text { Gait Rite System, Berg Balance Scale, TUG, } \\
\text { Balance Confidence Scale, modified } \\
\text { version of the Clinical Test of Sensory } \\
\text { Interaction and Balance }\end{array}$ & Pressure mat associated with computer games \\
\hline BIERYLA, 2013 [17] & 4 & $\begin{array}{l}\text { Berg Balance Scale; Fullerton Advanced } \\
\text { Balance Scale; Functional Range and TUG }\end{array}$ & $\begin{array}{l}\text { Nintendo Wii console associated with Balance } \\
\text { Board and Wii Fit games }\end{array}$ \\
\hline LAl, 2013 [20] & 8 & $\begin{array}{l}\text { Berg Balance Scale; Falls Efficacy Scale, } \\
\text { TUG and Force Platform for Static Balance }\end{array}$ & Xavix Measured Step System (XMSS) \\
\hline FRANCO, 2012 [14] & 7 & $\begin{array}{l}\text { Berg Balance Scale; Tinetti's Scale; } \\
\text { Quality of Life Questionnaire - SF36 }\end{array}$ & $\begin{array}{l}\text { Nintendo Wii console associated with Balance } \\
\text { Board and Wii Fit games }\end{array}$ \\
\hline TOULOTTE, 2012 [19] & 7 & $\begin{array}{l}\text { Unipedal Support; Tinetti's Scale and } \\
\text { Wii Fit test }\end{array}$ & $\begin{array}{l}\text { Nintendo Wii console associated with Balance } \\
\text { Board and Wii Fit games }\end{array}$ \\
\hline
\end{tabular}

*PS PEDro Scale. TUG Timed Up and Go test

test. The study included 86 elderly subjects, with a difference of $3.76( \pm 1.83)$ points in the scale; 64 individuals achieved an improvement of 2.16 ( \pm 1.13$)$ seconds in the test.

The meta-analysis for effectiveness of the intervention in improving the scores of the Berg Balance Scale was performed based on six articles [9, 10, 13-17] because the data were missing in $30 \%$. The SMD of the studies was -0.848 , contained in a $95 \%$ CI of -1.161 to -0.535 . The result refutes the null hypothesis and shows the efficacy in the rehabilitation of balance in the elderly through VRT.

Regarding the outcome of the Berg Balance Scale, the difference between means $(p=0.000)$ shows that there is a significant statistical difference in the final score of the scale between the pre- and post-intervention measures with VRT. There was no evidence of heterogeneity $\left(\mathrm{I}^{2}=\right.$ $\left.0.0 \%, p=0.666, \mathrm{Chi}^{2}: 3.03\right)$ between the studies. Table 3 presents the results with the synthetic measure of each study by comparing VRT with other therapies or placebo and shows the summary measure (SMD: $-0.858 ; 95 \%$ CI:-1.161; - 0.535), which indicates improvement by 5.31 points in the final score ( $\mathrm{Z}: 5.31, p=0.000)$.
Likewise, five studies [9, 10, 15-17] analyzed the time of the TUG test using VRT in the experimental group. As measured by the meta-analysis summary measure (0.894) and its respective confidence interval (95\% CI: $0.341,1.447)$, the value of the $I^{2}$ statistics $(46.4 \%, p=$ $0.114)$ and the tau-squared result $(0.1715)$, the improvement obtained showed an absence of heterogeneity, low variability between studies and evidence of a statistically significant difference in test execution speed (Z: $3.17 \mathrm{~s}$; $p=0.002$ ) (Table 4). The evaluation of the quality of the evidence, performed through the GRADE System, showed low and very low recommendation of the VRT based on improvements in the parameters of the Berg Scale and the TUG test, respectively (Table 5).

\section{Discussion}

This systematic review shows a shortage of intervention studies in the elderly using VRT, likely related to the great challenges of working with technological tools that have a playful character, the novelty of these products in the therapeutic market, the low knowledge of physiotherapists about the benefits of VRT, the preferences of professionals and users, the development and standardization of games 
Table 3 Standardized mean difference $(95 \% \mathrm{Cl})$ for the effect of virtual reality therapy on the Berg Balance Scale score, grouping data from six studies $(N=174)$

\begin{tabular}{|c|c|c|c|c|c|c|c|c|c|c|}
\hline \multirow{2}{*}{$\begin{array}{l}\text { Author, } \\
\text { year }\end{array}$} & \multirow[t]{2}{*}{ Therapy } & \multicolumn{3}{|c|}{ Pre-Intervention } & \multicolumn{3}{|c|}{ Post-Intervention } & \multirow[t]{2}{*}{ SMD $(95 \%$ CI $)$} & \multirow{2}{*}{$\begin{array}{c}\text { Study } \\
\text { weight } \\
(\%)\end{array}$} & \multirow{2}{*}{$\begin{array}{c}\text { SMD, Random } \\
\text { Effect Model, } \\
95 \% \text { CI }\end{array}$} \\
\hline & & Mean & SD & Total & Mean & SD & Total & & & \\
\hline Treml, 2013 & VRT vs proprioception & 52.75 & 4.37 & 16 & 55.5 & 1.07 & 16 & $-0.864(-1.591 ;-0.138)$ & 18.57 & \\
\hline Lee, 2013 & $\begin{array}{l}\text { VRT vs health } \\
\text { education }\end{array}$ & 51.67 & 2.48 & 27 & 53.41 & 1.89 & 27 & $-0.791(-1.341 ;-0.241)$ & 32.45 & \\
\hline Szturm, 2011 & VRT vs kinesiotherapy & 47.0 & 13.8 & 13 & 53.2 & 12.4 & 13 & $-0.474(-1.240 ; 0.293)$ & 16.70 & \\
\hline Bieryla, 2013 & VRT vs placebo & 50.0 & 2.82 & 4 & 53.0 & 1.4 & 5 & $-1.410(-2.918 ; 0.098)$ & 4.31 & \\
\hline Lai, 2013 & VRT vs placebo & 50.53 & 4.75 & 15 & 53.87 & 3.56 & 15 & $-0.796(-1.541 ;-0.050)$ & 17.64 & \\
\hline Franco, 2011 & VRT vs placebo & 48.0 & 3.7 & 11 & 52.0 & 0.8 & 10 & $-1.460(-2.434 ;-0.486)$ & 10.33 & \\
\hline Total & & & & 86 & & & 86 & $-0.848(-1.161 ;-0.535)$ & 100.0 & \\
\hline \multicolumn{11}{|c|}{ Heterogeneity: $\mathrm{I}^{2}=0.0 \%\left(\mathrm{p}=0.696 ;\right.$ tau $\left.^{2}=0.000\right)$} \\
\hline
\end{tabular}

to train functional tasks such as balance, gait and range and the design of clinical trials of high methodological quality [7].

Among the articles analyzed, the forms of intervention differed even in the presence of a similar outcome. Some studies were conducted with a more pragmatic therapeutic approach, with protocols varying according to the individual evaluation of the elderly [14, 18, 19]; others have established systematic, segmented and progressive protocols, including warm-up and isolated or combined exercises $[8,9,15-17,20]$. Another study had a protocol associating practice at home with the clinical environment [10].

The beneficial effects of VRT presented by the studies included in this systematic review extended to the outcomes of the balance variables, including mobility, flexibility [15], gait cadence and fear of falls [10]. There seems to be agreement among the authors about the positive results in these components; however, the meta-analysis evidenced possible discrepancies in the sample composition and the interventions.

Table 4 Standardized mean difference $(95 \% \mathrm{Cl})$ for the effect of virtual reality therapy on the time (in seconds) of the Timed Up and Go (TUG) test, grouping data from five studies $(N=131)$

\begin{tabular}{|c|c|c|c|c|c|c|c|c|c|c|}
\hline \multirow[t]{2}{*}{ Author, year } & \multirow[t]{2}{*}{ Therapy } & \multicolumn{3}{|c|}{ Pre-Intervention } & \multicolumn{3}{|c|}{ Post-Intervention } & \multirow[t]{2}{*}{ SMD $(95 \%$ CI $)$} & \multirow{2}{*}{$\begin{array}{c}\text { Study } \\
\text { weight } \\
(\%)\end{array}$} & \multirow{2}{*}{$\begin{array}{l}\text { SMD, Random Effect } \\
\text { Model, } 95 \% \text { CI }\end{array}$} \\
\hline & & Mean & SD & Total & Mean & SD & Total & & & \\
\hline $\begin{array}{l}\text { Mussato, } \\
2012\end{array}$ & VRT vs placebo & 8.2 & 0.4 & 5 & 6.8 & 0.5 & 5 & $3.092(1.135 ; 5.050)$ & 6.82 & \\
\hline Lee, 2013 & $\begin{array}{l}\text { VRT vs health } \\
\text { education }\end{array}$ & 11.48 & 2.31 & 27 & 9.78 & 1.58 & 27 & $0.862(0.308 ; 1.416)$ & 31.72 & \\
\hline Szturm, 2011 & $\begin{array}{c}\text { VRT vs } \\
\text { kinesiotherapy }\end{array}$ & 8.0 & 1.0 & 13 & 5.1 & 3.7 & 13 & $1.052(0.243 ; 1.861)$ & 23.30 & \\
\hline Bieryla, 2013 & VRT vs placebo & 12.8 & 1.9 & 4 & 11.2 & 2.61 & 4 & $0.686(-0.677 ; 2.049)$ & 12.17 & \\
\hline Lai, 2013 & VRT vs placebo & 9.54 & 3.52 & 15 & 8.54 & 2.85 & 15 & $0.312(-0.408 ; 1.033)$ & 26.00 & \\
\hline Total & & & & 64 & & & 64 & $0.894(0.341 ; 1.447)$ & 100.0 & \\
\hline
\end{tabular}

VRT: virtual reality exposure therapy; SD: standard deviation; SMD: standardized mean difference; CI: confidence interval. The mean of the measurement used to perform the test was in seconds. 
Table 5 GRADE system quality of evidence analysis for the Berg Balance Scale and the Timed Up and Go (TUG) test

\begin{tabular}{|c|c|c|c|c|c|c|c|c|}
\hline \multicolumn{7}{|l|}{ Quality assessment } & \multirow[t]{2}{*}{ Quality } & \multirow[t]{2}{*}{ Importance } \\
\hline Number of studies & Design & $\begin{array}{l}\text { Serious limitations } \\
\text { (risk of bias)? }\end{array}$ & $\begin{array}{l}\text { Inconsistency of } \\
\text { results (heterogeneity)? }\end{array}$ & Indirect evidence? & Inaccuracy? & Publishing bias? & & \\
\hline \multicolumn{9}{|l|}{ Berg Scale } \\
\hline 6 & $\begin{array}{l}\text { Quasi-experimental } \\
\text { studies and RCTs }\end{array}$ & No & No & No & Very important & $\mathrm{Sim}$ & $++/++++$ Low & Critical \\
\hline \multicolumn{9}{|l|}{ TUG Test } \\
\hline 5 & $\begin{array}{l}\text { Quasi-experimental } \\
\text { studies and RCTs }\end{array}$ & No & Low & No & Very important & Sim & $+++/++++$ Very Low & Critical \\
\hline
\end{tabular}

TUG Timed Up and Go

GRADE Grading of Recommendations Assessment, Development and Evaluation

The study by Holden [7] systematically reviewed the literature on interventions using VRT for balance and motor skills specifically for neurological disorders in individuals over 45 years of age. The authors note that for body balance, the three studies reported significant improvements in performance. Another important meta-analysis reported no significant effect of VRT [21] compared with traditional physical therapy or no intervention. However, the authors' review did not include the electronic databases SciELO and LILACS as a search source on the use of games in balance recovery.

Specifically concerning the interventions with emphasis on the improvement of static balance, Mussato and collaborators [9] have noted that the effect is more sensitive to detection in the baropodometry test since it measures maximum peaks and not the mean oscillation amplitude of the body balance. The games selected for this study offered medial-lateral and anteroposterior imbalances, thus stimulating the recruitment of motor strategies and allowing greater variability in the displacements of the pressure center in the orthostatic posture [22].

For gait training, Lobo [23] points out games for the rehabilitation of weight transfer abilities between limbs, unipedal support, triple flexion and load acceptance during initial support. However, other important aspects, such as dissociation of waists, impulsion and continuous anterior displacement of the center of mass, are not possible through VRT since the step change occurs in a stationary manner, which would justify the fact that Szturm [16] did not obtain a positive effect on the gait speed. In conventional rehabilitation, the stimuli are offered by the equipment through active dynamic training, and the proprioceptive inputs are produced by the efferent route [15]. Visualization of the action on the display (visual feedback) and interaction with the game stimulate proprioceptive inputs in a static manner.

The benefits noted in the aspects of static balance, gait components and sensorimotor integration show that the games provide training conditions that favor an integration between cognitive and motor stimulation. More complex training involving dual tasks, such as cognition and motor activity, requires automatic control during movements since the focus of attention is on the game shown on the display, thus promoting motor function improvement when compared with conventional training $[15,24]$.

Regarding falls, the training approaches of the articles included in this review aimed to increase or restore the self-confidence of the elderly. Individually, studies showed the superiority of VRT in recovering body balance when compared with conventional interventions, with impacts on the self-efficacy of post-intervention falls and not necessarily on the reduction in the number of falls.

Based on the health problems, it was noted that the designs aimed at prevention of falls and other conditions were evaluated in patients with Parkinson's disease. The study by Yen [18] resulted in improved sensory integration for postural control; however, the demand for attention was not altered after any VRT. Santana [25] and Loureiro [26], in experimental studies without a comparison group, concluded that training using the Nintendo Wii Fit Plus platform proved to be useful for the rehabilitation of degenerative diseases regarding motor performance, flexibility, lower limb joint stiffness and functional independence, in addition to improving the motor learning ability due to the cognitive stimuli provided by the videogame. The activation of neural circuits and structures by virtual games can play a key role in transferring the immediate effects of games to long-term effects. Lai [20] did not attribute maintenance of improvement to VRT per se; after the end of the interventions, the elderly improved their balance and felt confident to engage in physical activity, which justifies maintaining good results regarding balance.

Some methodological aspects were observed in the included clinical trials that reduce the risk of bias and allow better measurements when systematically adopted by the studies. All of them reported randomization, with well-established selection criteria for the participants, to increase the significance of the data, restricting populations with similar characteristics and guaranteeing homogeneity of the samples. Only two of the studies 
analyzed blinded one of the evaluators, an important item to be considered since this principle is used to avoid systematic errors in the research. Another aspect is intention-to-treat analysis, which also avoids distortions caused by a loss of participants, which may interrupt the equivalence established by randomized selection, reflecting non-adherence to treatment and potential benefits in individuals receiving the treatment established by the study.

The studies sought to guarantee homogeneity of the samples from systematic methods of development of clinical trials, in which the absence of heterogeneity in the articles was confirmed in the meta-analysis. However, we emphasize that there was a discrepancy in the individual results, which can be attributed to the size of the sample, the intensity of the intervention and differences in the participants' baseline risks. It is observed that the sample size and the number of sessions in the studies that were not effective in the balance of the elderly showed lower averages than those of effective studies. In relation to statistical power, only three articles $[8,10,18]$ performed the calculation, and it is not possible to state whether the absence of significant improvement due to the interventions in some studies occurred because of the lack of efficacy of the technique or because of the small sample size. The intervention protocol presented great variety regarding the number of sessions, weekly frequency, intervention time and isolated and/or combined exercises, and caution in decision making is required.

The literature evidenced dissent, and the dissemination of VRT was still incipient, which can also be demonstrated by the analysis of the quality of the evidence. According to evaluation criteria for recommending GRADE System evidence, the data selected to compose the meta-analysis may be influenced by publication bias, a tendency for published results to be systematically different from reality, as well as imprecision of the outcome measure and the sample size. Although there is a large body of literature on the role of physiotherapy in rehabilitating balance in the elderly and although studies published using VRT show positive results, the power of generalization is limited due to the samples sizes of the articles included in this review. Therefore, the results reflect a promising tool that requires more scientific investigations about the outcome to improve confidence in estimates of its effects. Future studies should specifically evaluate the types of protocol, as the need for advances in expanding the therapeutic armamentarium for rehabilitation practitioners is highlighted. To increase data reliability, new studies with sufficient sample size, better levels of evidence and methodological rigor are recommended in clinical trials demonstrating blinding techniques, intention-to-treat analysis, sample size and number of sessions to establish specific protocols of treatment. As a limitation of this study, we highlight the difficulty in exploring other domains of balance rehabilitation of the elderly, given the limited number of clinical trials included limiting the subgroup analysis, in addition to restriction to literature in English, Spanish and Portuguese.

Systematic review of clinical research on physiotherapeutic interventions with VRT in the rehabilitation of balance in the elderly emphasized relevance through the scenario of population aging resulting in unfavorable structural and functional changes predisposing elderly people to falls. Therefore, the therapeutic approach based on virtual reality is another alternative, which may, in addition to promoting motor control stimuli, help in gait efficiency and body balance. Because VRT is a playful method, it can encourage the participation of these individuals in activities of balance rehabilitation. Evidence of the results of virtual reality can awaken physiotherapists to broaden the scope of action in the provision of care during the rehabilitation of the elderly.

\section{Conclusion}

This review synthesized the effects of virtual reality therapy. Individually, there was concordance in the analyzed clinical trials regarding the improvements of static balance, gait components, sensorimotor integration and self-efficacy of falls, with no significant relevance for dynamic balance, gait speed and reduction in the number of falls. The data set evaluated in the meta-analysis and the quality of evidence analysis indicate the effectiveness of VRT in the treatment of balance and mobility in the elderly, but further studies are needed. Implications for clinical practice require caution in decision making because of sample profiles, intervention protocols and outcome measures. Regarding implications for the research, due to the lack of homogeneity in the methodologies, interventions and study outcomes in the studies, systematic positive effects were demonstrated for the mobility outcomes. The findings on using virtual reality therapy for recovery and balance training seem promising. However, to make assertions regarding effectiveness, adjustments are still needed for future studies.

\footnotetext{
Authors' contributions

The individual contributions of authors should be specified following: JSCdA made substantial contributions to conception and design, analysis and interpretation of data; been involved in drafting the manuscript or revising it critically for important intellectual content; given final approval of the version to be published. RCL made substantial contributions to conception and design, acquisition of data and interpretation of data; been involved in drafting the manuscript or revising it critically for important intellectual content; given final approval of the version to be published. RB made substantial contributions to conception and design, acquisition of data and interpretation of data; been involved in drafting the manuscript or revising it critically for important intellectual content; given final approval of the version to be published.
} 
CYY made substantial contributions to conception and design and interpretation of data; been involved in drafting the manuscript or revising it critically for important intellectual content; given final approval of the version to be published.

\section{Ethics approval and consent to participate}

Our manuscript is systematic review and metanalysis with data collection from the literature, without involvement direct collection involving humans Therefore, there is no appraisal by ethics committee.

\section{Competing interests}

The authors declare that they have no competing interests.

\section{Publisher's Note}

Springer Nature remains neutral with regard to jurisdictional claims in published maps and institutional affiliations.

\section{Author details}

${ }^{1}$ Ciências da Reabilitação, Instituto Federal de Educação, Ciência e Tecnologia do Rio de Janeiro - IFRJ, Rio de Janeiro, RJ, Brasil. ${ }^{2}$ Centro Universitário Filadélfia - UNIFIL, Londrina, PR, Brasil. ${ }^{3}$ Saúde Coletiva, Centro Universitário Filadélfia - UNIFIL, Londrina, PR, Brasil. ${ }^{4}$ Colina, Manhuaçu, Brazil.

Received: 2 April 2018 Accepted: 1 June 2018

Published online: 31 July 2018

\section{References}

1. Bruniera CAV, Rodacki ALF. Respostas estabilométricas de jovens e idosos para recuperar o equilíbrio após uma perturbação inesperada controlada. Rev Educ Fis UEM. 2014;25(3):345-51.

2. Meireles AE, Pereira LVS, Oliveira TG, Christofoletti G, Fonseca AL. Alterações neurológicas fisiológicas ao envelhecimento afetam o sistema mantenedor do equilíbrio. Rev Neurocienc. 2010;18(1):103-8.

3. Pícoli TS, Figueiredo LL, Patrizzi $\sqcup$. Sarcopenia e envelhecimento. Fisioter Mov. 2011;24(3):455-62.

4. Teixeira INAO, Guariento ME. Biologia do envelhecimento: teorias, mecanismos e perspectivas. Ciênc Saúde Coletiva 2010. 2016;15(6):2845-57.

5. Gontijo RW, Leão MRC. Eficácia de um programa de fisioterapia preventiva para idosos. Rev Méd Minas Gerais. 2013;23(2):173-80.

6. Keshner EA. Virtual reality and physical rehabilitation: a new toy or a new research and rehabilitation tool? J Neuroeng Rehabil 2004. 2016:3(1):8.

7. Holden MK. Virtual environments for motor rehabilitation: review. Cyberpsychol Behav. 2005;8(3):187-211.

8. Rendon AA, Lohman EB, Thorpe D, Johnson EG, Medina E, Bradley B. The effect of virtual reality gaming on dynamic balance in older adults. Age Ageing. 2012;41(4):549-52.

9. Mussato R, Brandalize D, Brandalize M. Nintendo Wii e seu efeito no equilíbrio e capacidade funcional de idosos saudáveis. Rev Brasil Ciência Mov 2012. 2016;20(2):68-75.

10. Lee S, Shin S. Effectiveness of virtual reality using video gaming. Diabetes Technol Ther. 2013;15(6):489-96.

11. Shiwa SR, Costa LOP, Moser ADL, Aguiar IC, Oliveira LVF. PEDro: a base de dados de evidências em fisioterapia. Fisioter Mov. 2011;24(3):523-33.

12. Higgins JPT, Green S. Cochrane handbook for systematic reviews of interventions 4.2.6 [updated September 2006]. In: The Cochrane Library, Issue 4. Chichester: John Wiley \& Sons, Ltda; 2006.

13. Brasil. Ministério da Saúde. Diretrizes metodológicas: elaboração de pareceres técnicos-científicos. 3rd ed. Brasilia: Ministério da Saúde; 2011. 80p.: il.

14. Franco JR, Jacobs K, Inzerillo C, Kluzik J. The effect of the Nintendo Wii fit and exercise in improving balance and quality of life in community dwelling elderls. Technol Health Care. 2012;20(2):95-115.

15. Treml CJ, Kalil Filho FA, Ciccarino RFL, Wegner RS, Saita CYS, Corrêa AG. O uso da plataforma Balance Board como recurso fisioterápico em idosos. Revbrasgeriatrgerontol. 2012;16(4):759-68.

16. Szturm T, Betkler AL, Moussavi Z, Desai A, Goodeman V. Effects of an interactive computer game exercise regimen on balance impairment in frail community-dwelling older adults: a randomized controlled trial. Phys Ther. 2011;91(10):1449-62.

17. Bieryla KA, Dold NM. Feasibility of Wii fit training to improve clinical measures of balance in older adults. Clin Interv Aging. 2013;8:775-81.
18. Yen CY, Lin KH, Hu MH, Wu RM, Lu Tw LCH. Effects of virtual realityaugmented balance training on sensory organization and attentional demand for postural control in people with Parkinson disease: a randomized controlled trial. Phys Ther. 2011;91(6):862-74.

19. Toulotte C, Toursel C, Olivier N. Wii fit training vs. adapted physical activities: which one is the most appropriate to improve the balance of independent senior subjects? A randomized controlled study. Clin Rehabil. 2012;26(9):827-35.

20. Lai CH, Peng CW, Chen YL, Huang CP, Hsiao YL, Chen SC. Effects of interactive video-game based system exercise on the balance of the elderly. Gait Posture. 2013:37(4):511-8.

21. Booth V, Masud T, Connell L, Bath-Hextall F. The effectiveness of virtual reality intervention in improving balance in adults with impaired balance compared with standard or no treatment: a systematic review and metaanalysis. Clin Rehabil. 2014;28(5):419-31.

22. Ricci NA, Gazzola JM, Coimbra IB. Sistemas sensoriais no equilíbrio corporal de idosos. Arq Bras Ciên Saúde. 2009;34(2):94-100.

23. Lobo AM. Efeito de um Treinamento em Ambiente Virtual Sobre o Desempenho da Marcha e Funções Cognitivas em Idosos Saudáveis. 2013. 112 f. São Paulo: Dissertação (Mestrado em Psicologia) - Universidade de São Paulo; 2013.

24. Silva, K. G. Efeito de um Treinamento com o Nintendo Wii® Sobre o Equilíbrio Postural e Funções Executivas de Idosos Saudáveis - Um Estudo Clinico Longitudinal, Controlado e Aleatorizado. 2013. 128 f. Dissertação (Mestrado em Psicologia) - Universidade de São Paulo, São Paulo, 2013.

25. Santana CMF, Lins OG, Sanguinetti DCM, Silva FP, Angelo TDA, Cariolano MGWS, Câmara SB, Silva JPA. Efeitos do tratamento com realidade virtual não imersiva na qualidade de vida de indivíduos com Parkinson. Revbrasgergerontol. 2015;18(1):49-58.

26. Loureiro APC, Ribas CG, Zotz TGG, Chen R, Ribas F. Viabilidade da terapia virtual na reabilitação de pacientes com doença de Parkinson: estudopiloto. Fisioter. Mov. 2012;25(3):659-66.

\section{Ready to submit your research? Choose BMC and benefit from:}

- fast, convenient online submission

- thorough peer review by experienced researchers in your field

- rapid publication on acceptance

- support for research data, including large and complex data types

- gold Open Access which fosters wider collaboration and increased citations

- maximum visibility for your research: over $100 \mathrm{M}$ website views per year

At BMC, research is always in progress.

Learn more biomedcentral.com/submissions 